\title{
Incidência de meningite por Haemophilus influenzae no RS 1999-2010: impacto da cobertura vacinal
}

\author{
Incidence of meningitis caused by Haemophilus influenzae \\ in the state of Rio Grande do Sul 1999-2010: \\ impact of vaccination campaign
}

João Guilherme Stadler Schossler ${ }^{1}$

Sandra Trevisan Beck ${ }^{1}$

Marli Matiko Anraku de Campos ${ }^{1}$

Lourdes Boufleur Farinha ${ }^{2}$

${ }^{1}$ Departamento de Análises Clínicas e Toxicológicas, Centro de Ciências da

Saúde, Universidade Federal de Santa Maria. Av. Roraima s/n. Prédio 26/CCS,

Camobi. 97105-900 Santa Maria RS.

joaogss_med@hotmail.com

${ }^{2} 4{ }^{\mathrm{a}}$ Coordenadoria

Regional de Saúde do Rio

Grande do Sul.

\begin{abstract}
This article seeks to analyze and update the epidemiological situation of meningitis caused by Haemophilus influenzae type $b$ in the past 10 years in the state of Rio Grande do Sul (RS). It is a retrospective, descriptive study, which used the data notification system of meningitis and vaccination campaign coverage, stored in the Epidemiological TABNET online database, for the period from 1999 to 2010. Cases notified and confirmed were used and the selection criteria were the year when the symptoms were detected, age, diagnosis, and evolution. Nineteen health centers in the state of Rio Grande do Sul were analyzed. The z-test was used to evaluate comparisons between the proportions. In the period studied, 3043 confirmed cases of bacterial meningitis were reported, of which $6.77 \%$ were caused by $\mathbf{H}$. influenzae. The incidence and mortality rates of meningitis caused by $\mathbf{H}$. influenzae, without taking age group into consideration, fell significantly (95.6\%) after 1999. Children under one year old continue to be the most affected (52\%), there being no change in lethality. The results presented revealed a positive impact of $\mathrm{Hib}$ vaccination strategies in the state of Rio Grande do Sul over the past ten years.
\end{abstract}

Key words Meningitis, Haemophilus influenzae, Epidemiology, Vaccination, Rio Grande do Sul
Resumo Oobjetivo deste artigo é analisar e verificar a situação epidemiológica das meningites causadas pelo agente Haemophilus influenzae tipo b nos últimos 10 anos no Rio Grande do Sul. Estudo retrospectivo, descritivo, utilizando o sistema de dados de notificação de meningites, e cobertura vacinal, armazenados em base on line Tabnet - Tabulação de dados Epidemiológicos CEVS/SES/RS, abrangendo o período de 1999 a 2010. Foram utilizados casos notificados e confirmados, tendo como critério de seleção o ano de inicio dos sintomas, idade, diagnostico e evolução. Foi analisado o Estado do Rio Grande do Sul, representado por 19 coordenadorias de saúde. Comparações entre proporções foram avaliadas pelo teste de z. No RS foram notificados 3043 casos confirmados de meningite bacteriana, sendo $6,77 \%$ dos casos causados por $\boldsymbol{H}$. influenzae. $O$ coeficiente de incidência da meningite por $\boldsymbol{H}$. influenzae, sem considerar faixa etária, caiu significativamente (95,6\%) após 1999, assim como a mortalidade. Crianças menores de um ano continuam sendo as mais acometidas (52\%), não havendo alteração na letalidade. Os resultados apresentados revelaram um impacto positivo das estratégias de vacinação contra Hib no Estado do Rio Grande do Sul nos últimos dez anos.

Palavras-chave Meningite, Haemophilus influenzae, Epidemiologia, Vacinação, Rio Grande do Sul 


\section{Introdução}

Haemophilus influenzae é uma bactéria Gram negativa que coloniza de forma assintomática a nasofaringe de indivíduos saudáveis e, ocasionalmente, provoca doenças sistêmicas e infecções das mucosas. Algumas espécies de Haemophilus fazem parte da microbiota do aparelho respiratório superior dos seres humanos, sendo que o H. influenzae é a espécie mais comum. Presente em pequena quantidade constitui um dos microrganismos potencialmente patogênicos do biofilme que recobre as mucosas da boca e do trato respiratório, composto por centenas de espécies bacterianas ${ }^{1,2}$. Algumas cepas de $H$. influenzae apresentam em sua estrutura, cápsula polissacarídica que é considerada o maior fator de virulência daquelas que causam infecção sistêmica. Existem seis sorotipos capsulares distintos designados de "a" até "f" que podem ser sorotipadas com base no antígeno específico de suas cápsulas ${ }^{1}$. Mais de $90 \%$ das cepas de $H$. influenzae tipo $\mathrm{b}(\mathrm{Hib})$ produzem uma bacteriocina conhecida como hemocina, que não é produzida pelas cepas acapsuladas de $H$. influenzae ou sorotipo diferente do b. Este fator pode contribuir para a habilidade do Hib em competir efetivamente com as cepas que colonizam a nasofaringe e são sensíveis ao efeito letal da hemocina ${ }^{3}$. Desta forma, as cepas encapsuladas, especialmente as do sorotipo b (Hib), acabam sendo responsáveis por uma variedade de doenças invasivas, sendo a mais importante delas a meningite.

As meningites bacterianas agudas constituem importante causa de morbimortalidade na infância. Neste contexto, o Hib é uma das bactérias mais importantes entre as infecções bacterianas invasivas em crianças no mundo todo. $\mathrm{Na}$ América Latina ${ }^{4}$, e nos países em desenvolvimento, chega a causar $30 \%$ dos casos de pneumonia com cultura positiva e de 20 a $60 \%$ dos casos de meningite bacteriana, onde apresenta uma taxa de letalidade que atinge $40 \%{ }^{5}$. Tem sido objeto de interesse crescente, devido à gravidade das doenças por ele causadas, e de suas subsequentes sequelas ${ }^{6}$. Entre as doenças invasivas causadas por $H i b$, a meningite é a que apresenta melhor possibilidade de vigilância e controle, devido à obrigatoriedade da notificação e à hospitalização dos casos e por ser o agente, passível de controle através de imunização eficaz?

O expressivo impacto da introdução da vacina conjugada $H i b$ na redução das doenças invasivas está bem documentado em regiões industrializadas como Estados Unidos e diversos paí- ses da Europa e, mais recentemente, em alguns locais da América Latina ${ }^{8}$. No Brasil, a vacina contra o Hib foi incorporada à rotina do programa nacional de imunizações em meados de 1999 e o impacto da vacinação já tem sido descrito por alguns pesquisadores ${ }^{9,10}$. Em fevereiro de 2002, passou a fazer parte dos imunobiológicos disponíveis na rede pública a Vacina Combinada contra Difteria, Tétano, Coqueluche e Haemophilus influenzae tipo b (DTP + Hib) para utilização apenas em crianças menores de um ano de idade, para início ou complementação do esquema básico de vacinação ${ }^{11}$. Contudo, o impacto causado pela vacinação precisa ser monitorado, pois algumas variáveis como cobertura vacinal, aderência da população, conservação e técnica de administração da vacina, podem modificar o cenário favorável com o decorrer do tempo. No Rio Grande do Sul, um dos últimos estudos publicados sobre a incidência de meningite por $\mathrm{Hib}$ no estado data de $2001^{12}$, sendo, portanto, importante uma análise da situação epidemiológica deste agente infeccioso nos últimos 10 anos.

\section{Material e métodos}

Foi realizado um estudo retrospectivo, descritivo, utilizando o sistema de dados de notificação de meningites, e cobertura vacinal, armazenados em base on line Tabnet - Tabulação de dados Epidemiológicos - CEVS/SES/RS, abrangendo o período de 1999 a 2010. Estes dados estão registrados no sistema de informação de agravo de notificação (SINAN) após resultado da análise dos exames laboratoriais dos casos suspeitos (realizado em liquor, soro, e sangue) pelos laboratórios locais e laboratório de referência estadual (LACEN-RS).

O número de casos confirmados de cada meningite por $H$. influenzae foi obtido através dos casos notificados no SINAN, utilizando como critério de seleção, o ano de inicio dos sintomas. Este critério foi cruzado com idade, diagnóstico-etiologia e evolução. Foi analisado o Estado do Rio Grande do Sul, representado por 19 coordenadorias de saúde.

Para cálculo dos coeficientes de incidência foi utilizada a estimativa populacional total e por faixa etária, obtidas do Instituto Brasileiro de Geografia e Estatística (IBGE).

Comparações entre proporções foram avaliadas pelo teste de z. Valores de $\mathrm{p}<0,05$ foram considerados estatisticamente significantes. 


\section{Resultados}

No Rio Grande do Sul (RS) no período de 1999 a 2010 foram notificados 3043 casos identificados e confirmados de meningite bacteriana, não tuberculosa. Entre estas, $6,77 \%$ dos casos foram causados por $H$. influenzae. Na região de abrangência da $4{ }^{\text {a }}$ CRS, centro do RS, a frequência foi semelhante, apresentando $8,8 \%$ dos casos de meningite pelo mesmo agente etiológico, sendo importante ressaltar que a partir de 2005 não houve notificação de casos novos casos nesta região. O coeficiente de incidência da meningite por $\mathrm{H}$. influenzae, sem considerar faixa etária, que era semelhante à meningite por Streptococus pneumoniae, caiu significativamente $(95,6 \%)$ após 1999 , passando de 0,82/100.000 habitantes para 0,036/ 100.000 habitantes em 2009 ( $p>0,01$ ) (Figura 1).

A análise por faixa etária evidencia queda significativa do coeficiente de incidência de menin-

gite por $H$. influenzae principalmente em crianças com menos de um ano de idade, embora este continue ser o grupo mais acometido. Dos 208 casos de meningite por Hib notificados no RS no período estudado, $52 \%$ ocorreram em crianças com menos de um ano, $30 \%$ na faixa etária entre um a quatro anos, e $18 \%$ em indivíduos com idade igual ou superior a cinco anos. (Figura 2).

Outras meningites bacterianas como a causada por Streptococus pneumoniae e Neisseria meningitidis, em crianças com menos de um ano de idade, também mostraram queda na incidência, embora de forma menos significativa (Figura 3), corroborando que a queda na incidência de meningite por $H i b$ foi devida à vacinação, $\mathrm{e}$ não por subnotificação.

Apesar da incidência da Meningite por Hib ter diminuído nos últimos anos devido à vacinação, a letalidade continua importante, não tendo havido mudança no perfil apresentado por este agente nos últimos 10 anos, a não ser de forma pontual. Em 1999 o Coeficiente de Letalidade (CL) era de 13,25 , apresentou um aumento significativo em 2005 (CL:40), e 2009 (CL:50), voltando a 12,5 em 2010 (Figura 4).

Porém, como esperado, uma mudança importante ocorreu no índice de mortalidade, principalmente na faixa etária inferior a um ano de idade.

O programa de imunizações tem apresentado um bom desempenho no decorrer dos últimos anos. Isto pode ser observado pelo numero de nascidos vivos a cada ano relacionado com o número de doses de vacinas aplicadas (Figura 5). Verifica-se que, a partir de 2003, a eficiente cober-

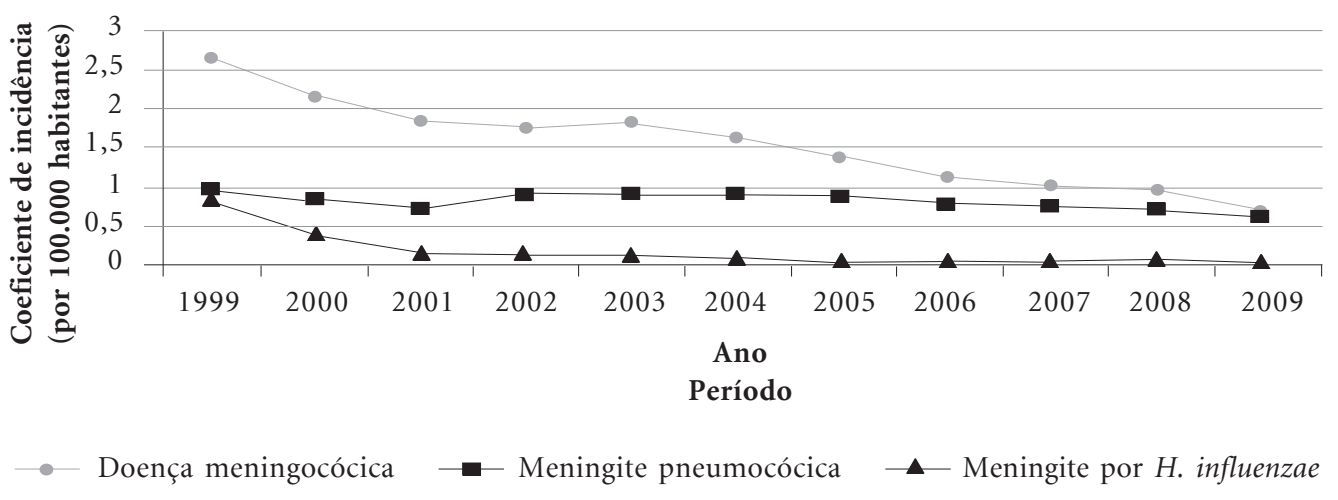

Figura 1. Distribuição dos coeficientes de incidência por etiologia das principais meningites bacterianas, não tuberculosa, no RS. 


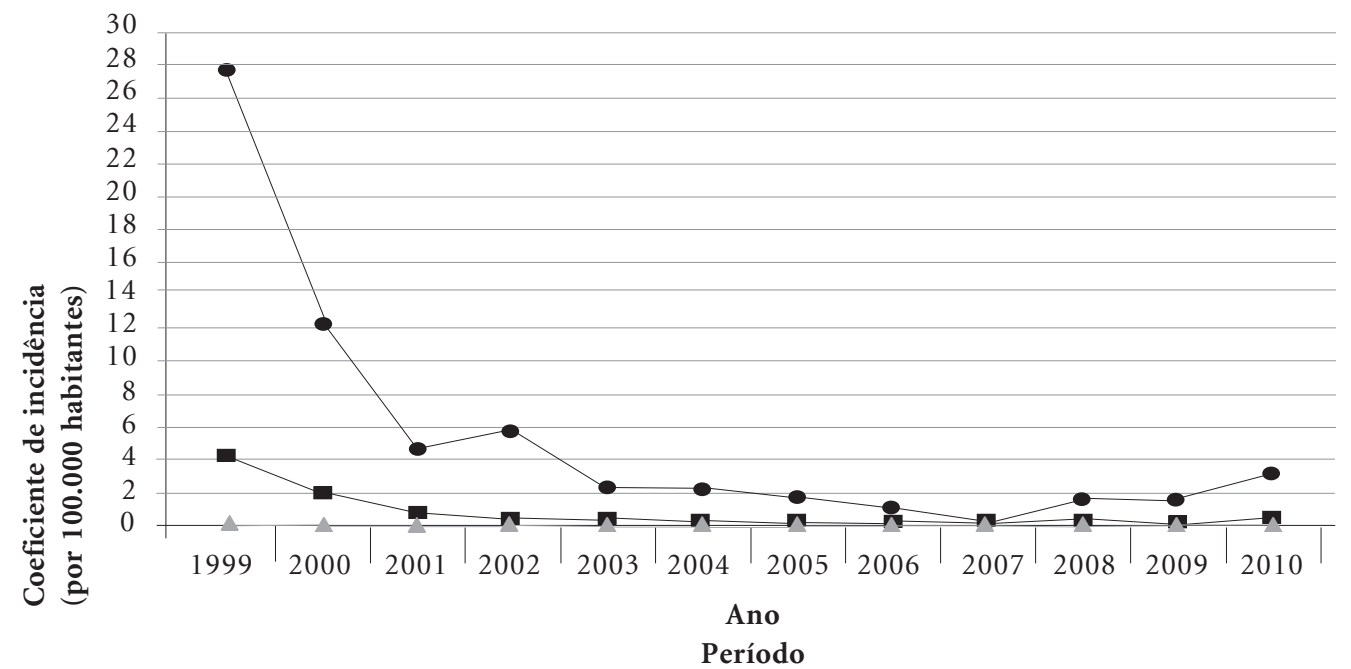

$\longrightarrow<1$ ano $\longrightarrow 1$ a 4 anos $->5$ anos

Figura 2. Distribuição por faixa etária dos coeficientes de incidência de Meningites por Haemophylus influenzae no RS entre 1999 a 2010.

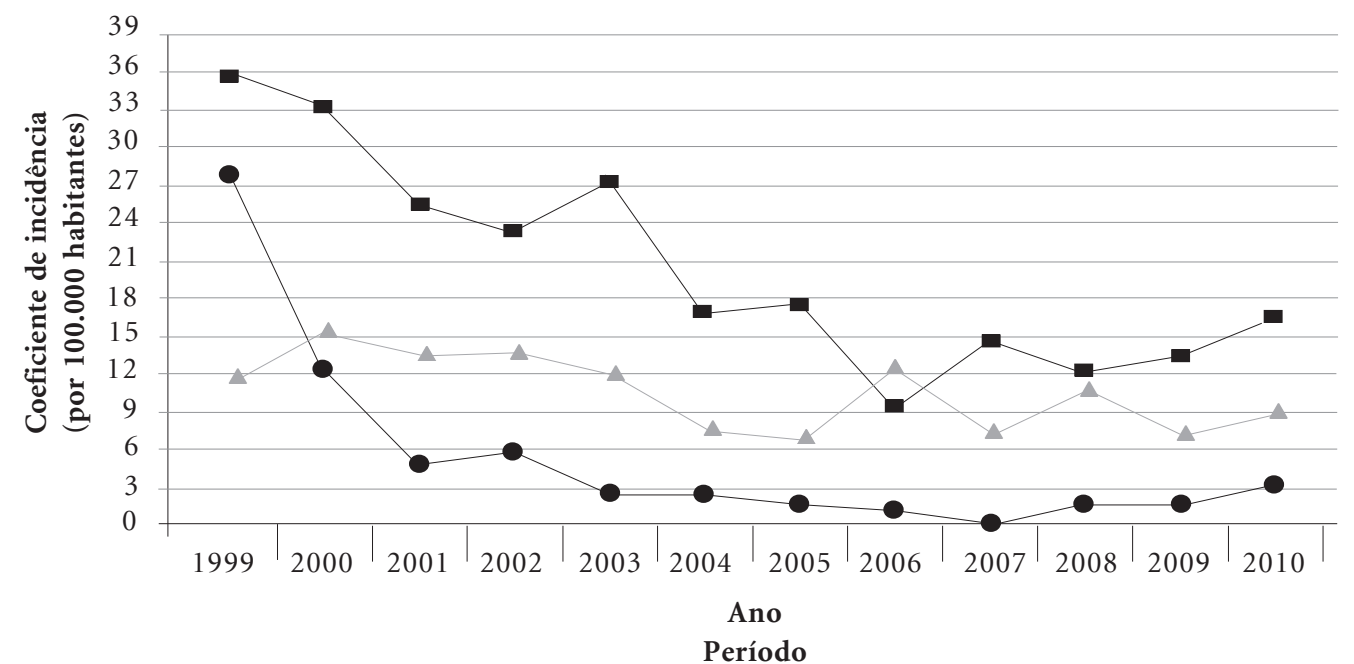

$\longrightarrow$ Meningite por $H$. influenzae $\rightarrow$ Doença meningocócica $\longrightarrow$ Meningite pneumocócica

Figura 3. Distribuição por faixa etária dos coeficientes de incidência de Meningites por Haemophylus influenzae no RS entre 1999 a 2010.

tura vacinal pela vacina combinada contra Difteria Tétano e Coqueluche $(\mathrm{DTP})+$ Hib resultou em um pequeno numero de casos, onde foi necessária a utilização da vacina individual (Hib). 


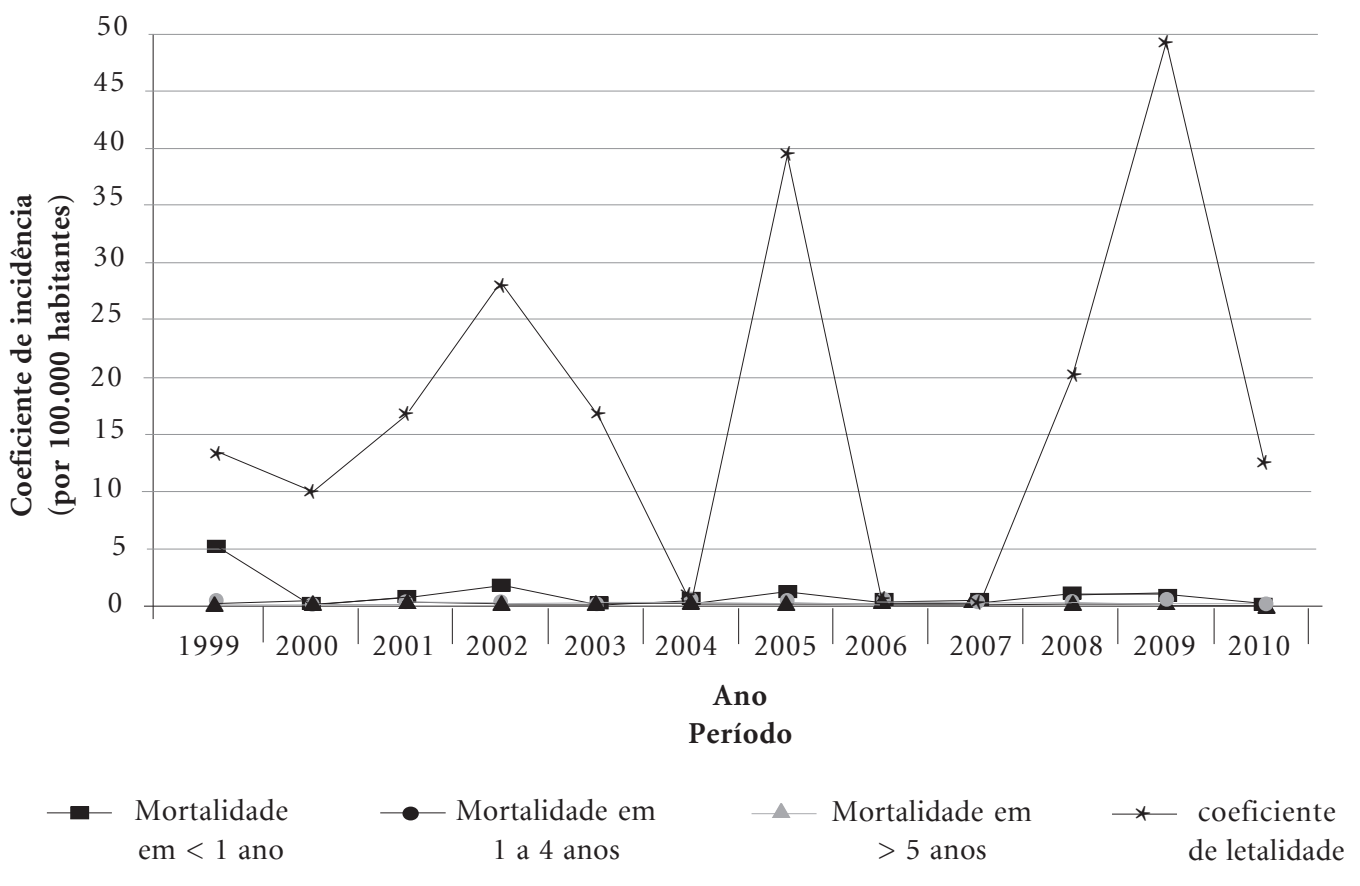

Figura 4. Distribuição dos coeficientes de letalidade geral e mortalidade por faixa etária de meningites por Haemophylus influenzae entre 1999 a 2010 no RS.

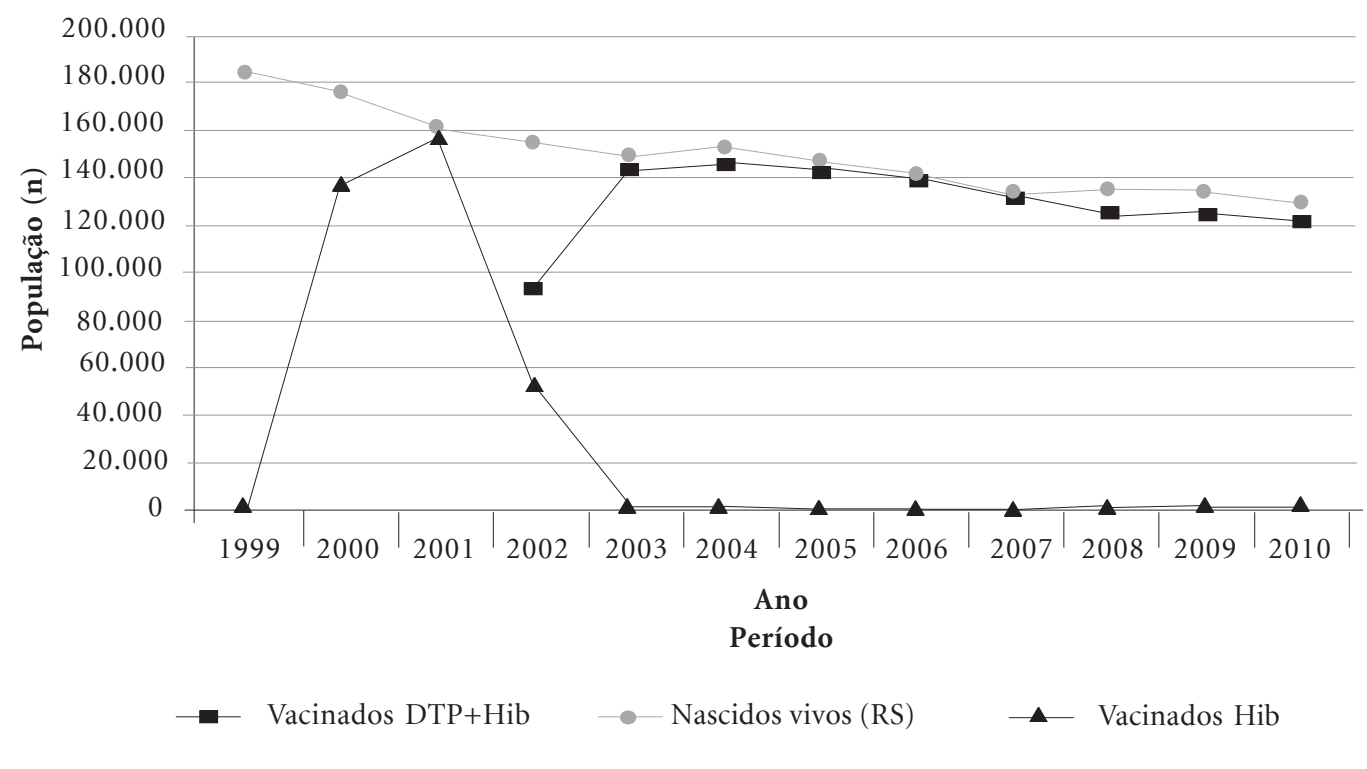

Figura 5. Cobertura vacinal contra Haemophylus influenzae no Rio Grande do Sul.

\section{Discussão}

Para o controle das meningites causadas pelo $\mathrm{Hib}$, a vacina conjugada com o toxóide tetânico, in- troduzida na rotina do Programa Nacional de Imunizações no segundo semestre de 1999, foi um instrumento importante. Antes do uso de vacinas específicas, este patógeno foi a causa mais 
frequente de meningite bacteriana em crianças menores de um ano de idade, em diversas regiões do mundo ${ }^{13,14}$.

No Brasil, a meningite por Hib é uma doença endêmica cujo patógeno não causa epidemias, ainda que possam ocorrer conglomerados de $\operatorname{casos}^{15}$. Em relação às outras meningites bacterianas, até 1999, o Hib representava a $2^{\text {a }}$ causa depois da doença meningocócica. A partir do ano 2000, após a introdução da vacina conjugada contra o Hib, a segunda maior causa de meningites bacterianas passou a ser representada pelo $S$. pneumoniae ${ }^{16}$. No RS, entre as crianças com menos de um ano de idade, pode ser observado o mesmo padrão descrito acima. Contudo, no ano de 2006, as meningites causadas pelo $S$. pneumoniae, nesta faixa etária, ocuparam o primeiro lugar em incidência. Nos anos seguintes, a meningite meningocócica voltou a ser a infecção com maior coeficiente de incidência, embora apresentando menor diferença entre os índices encontrados, comparando-se o ano de 2000 com 2010. Nota-se uma queda na incidência de meningite meningocócica e uma estabilização da meningite por S. pneumoniae (Figura 3). Nos próximos anos espera-se que ocorra uma alteração neste perfil, com a introdução no sistema único de saúde, em 2010, da vacina pneumocócica conjugada, a qual, diferente da vacina polissacaridica comum, é capaz de diminuir o número de indivíduos colonizados ${ }^{17}$.

A vacinação, além de conferir proteção direta aos indivíduos imunizados, minimiza os danos produzidos pelo patógeno, através da redução da prevalência de microorganismos circulantes entre as pessoas. Consequentemente, as crianças não vacinadas acabam tendo uma proteção adicional, por menor risco de exposição ao Hib o que pode ser denominado de "efeito rebanho"18. Isto pode ser observado no presente estudo, através da baixa incidência de meningite por Hib encontrada em indivíduos com mais de cinco anos de idade (Figura 2).

A vacinação contra Hib, no Brasil, levou a uma queda de $90 \%$ na incidência de meningites por este agente. No RS, no período estudado, 6,7\% das meningites notificadas em todas as faixas etárias, foram por Hib. Após 1999, a Figura 1 mostra claramente queda de 95,6\% na incidência, porém o predomínio da infecção continuou a ser na faixa etária de indivíduos com menos de cinco anos de idade, onde ocorreram $82 \%$ das meningites por Hib (Figura 2). Esta mesma proporção foi encontrada por Miranzi et al. ${ }^{19}$, estudando o período de 1983 a 2002 em Minas Gerais. As altas taxas de doenças invasivas ocasionadas por $H$. influenzae são observadas principalmente em populações com contatos frequentes ou que estejam em exposição prolongada ao microrganis$\mathrm{mo}^{20}$. Embora a relação entre colonização e manifestação de infecções não sejam diretamente proporcionais, a colonização da nasofaringe é fator indispensável para que ocorra a infecção ${ }^{21}$. As condições locais, (condições socioeconômicas desfavoráveis, permanência em creches, locais fechados) também representam fatores importantes para o aumento do número de indivíduos colonizados ${ }^{22}$. Entre os fatores que favorecem a passagem da colonização para a infecção, a idade é o mais relevante, uma vez que crianças com menos de cinco anos de idade apresentam pico de incidência da infecção ao redor dos dois anos ${ }^{23}$.

Dados recentes de vigilância conduzida na região central do Brasil mostraram que a taxa de mortalidade por doença bacteriana invasiva em crianças de 2 a 23 meses caiu de 72,8 para 49,0 por 100.000 crianças-ano de observação, após o segundo ano da introdução da vacina $H i b$. A maior redução foi observada na mortalidade por meningite bacteriana ${ }^{24}(12,8$ para $3,5 / 100.000)$. No RS, o coeficiente de mortalidade por Hib caiu de 5,2 para 0,78 por 100.000 crianças de 1999 até 2009. Na Figura 4, pode ser observado que a mortalidade segue a tendência da letalidade, corroborando a importância da prevenção deste agravo. Após 2003, notam-se pequenas variações no índice de incidência, contudo, a vigilância torna-se necessária devido ao risco de reaparecimento de cepas de Hib. No Alasca, este fato ocorreu devido à vacina conjugada que estava sendo utilizada apresentar uma baixa capacidade de indução do sistema imune entre os nativos, sendo sugerida a sua substituição por outra. Além disso, as cepas encontradas como infectantes também foram recuperadas como colonizadoras em $74 \%$ da população ${ }^{25}$.

No Brasil, a análise de cepas de $H$. influenzae recuperadas de pacientes com meningite, permitiu a verificação da ocorrência de substituição de sorotipo invasivo $b$ por sorotipo $\mathrm{a}^{9}$, portanto o monitoramento e o estudo de cepas circulantes na população infantil saudável representam um aspecto epidemiológico bastante importante. Além disto, alguns estudos relatam que mesmo após a vacinação, as cepas de sorotipo b ainda podem ser recuperadas por determinado tempo $^{26,27}$, enquanto o nível adequado de imunidade da população não é alcançado. Na Inglaterra, após o ressurgimento de meningites provocadas por Hib, foi realizada uma campanha de vacinação entre crianças com menos de cinco anos, com 
a introdução de uma quarta dose de vacina anti Hib, como dose de reforço ${ }^{28}$.

A vacina para Hib é decorrente da conjugação do polissacarídeo capsular com uma proteína (toxóide diftérico ou tetânico). Essa conjugação foi necessária para recrutar células $\mathrm{T}$ para a resposta imunológica primária, o que o polissacarídeo isolado não é capaz de fazer durante os dois primeiros anos de vida. No Brasil, o esquema vacinal adotado pelo Ministério da Saúde consiste na aplicação de três doses da vacina combinada DTP + Hib, com intervalo de 60 dias (mínimo de 30 dias), a partir de 2 meses de idade. Após os 12 meses de idade, todas as doses necessárias de DTP e Hib, para início ou complementação do esquema básico e reforços, são realizadas com as apresentações tradicionais (em separado) já disponíveis na rede pública. Ressalte-se que a administração da vacina contra Hib só está indicada para crianças de 1 a 4 anos, quando estas não receberam o esquema completo antes do primeiro ano de vida, ou seja, 3 doses. Nestas situações recomenda-se a aplicação de uma única dose ${ }^{11}$.

No RS, a cobertura vacinal tem sido satisfatória se for considerado o baixo coeficiente de incidência de meningite por Hib e a correlação positiva entre o número de doses vacinais aplicadas e o numero de nascidos vivos, nos últimos anos (Figura 5).

\section{Considerações finais}

Uma vez que a meningite por Haemophylus influenzae b encontra-se classificada na lista de mortes evitáveis em menores de cinco anos de idade, reduzíveis por imunoprevenção ${ }^{29}$, considera-se que o monitoramento da incidência, da letalidade e da mortalidade desta morbidade deva ser de caráter contínuo. Os resultados aqui apresentados revelaram um impacto positivo das estratégias de vacinação contra Hib no Estado do Rio Grande do Sul nos últimos dez anos. Este estudo foi possível devido à considerável qualidade e confiabilidade dos dados publicados no Sistemas de Informação em Saúde (SIS), que permite o acesso ao Sistema de Informação de Mortalidade (SIM), SINAN (sistema de informação de agravo de notificação) e ao Sistema de Informação de Nascidos Vivos (SINASC) do estado.

\section{Colaboradores}

JGS Schossler, ST Beck, MMA Campos e LB Farinha participaram igualmente de todas as etapas de elaboração do artigo.

\section{Referências}

1. Koneman EW, Allen SD, Janda WM, Schreckenberger PC, Winn WC. Haemophilus. Color atlas and textbook of diagnostic microbiology. $5^{\text {th }}$ Edition. Philadelphia: Lippincott-Raven publishers; 1997.

2. Klein JO. Role of nontypeable Haemophilus influenzae in pediatric respiratory tract infections. Pediatr Infect Dis J 1997; 16(2):5-8.

3. Lipuma JJ, Richman H, Stull TL. Haemocin, a bacteriocin produced by Haemophilus influenzae type b species distribution and role in colonization. Infect Immun 1990; 58(6):1600-1605.

4. Andrade ALSS, Brandileone MC, DiFabio JL, Oliveira RM, Silva AS, Baiocchi SS, Martelli CM. Haemophilus influenzae resistance in Latin America: systematic review of surveillance data. Microb Drug Resistance 2001; 7(4):403-411.

5. Funkhouser A, Steinhoff CM, Ward J. Haemophilus influenzae disease and immunization in developing countries. Rev Infect Dis 1991; 13(Supl. 6):542-554.

6. World Health Organization (WHO). Generic protocol for population-based surveillance of Haemophilus influenzae type $b$. Centers for Diseases Control and Prevention. Geneva: WHO; 1996.

7. Miranzi SSC, Camacho LAB, Valente JG. Haemophilus influenzae tipo b: situação epidemiológica no estado de Minas Gerais, Brasil, 1993 a 1997. Cad Saude Publica 2003; 19(5):1267-1275. 
8. Peltola H. Worldwide Haemophilus influenzae type b disease at the beginning of the 21st century: global analysis of the disease burden 25 years after the use of the polysaccharide vaccine and a decade after the advent of conjugates. Clin Microbiol Rev 2000; 13(2):302-317.

9. Ribeiro GS, Reis JN, Cordeiro SM, Lima JB, Gouveia EL, Petersen M, Salgado K, Silva HR, Zanella RC, Almeida SC, Brandileone MC, Reis MG, Ko AI. Prevention of Haemophilus influenzae type b (Hib) meningitis and emergence of serotype replacement with type a strains after introduction of Hib immunization in Brazil. J Infect Dis 2003; 187(1):109-116.

10. Takemura NS, Andrade SM. Meningite por Haemophilus influenzae tipo b em cidades do estado do Paraná, Brasil. J Pediatria 2001; 77(5):387-392.

11. Centro de Vigilância Epidemiológica. Vacina Tetravelante- Informe Técnico. São Paulo: CVE 2002. [acessado 2011 maio 31]. Disponível em: http: ftp:/ /ftp.cve.saude.sp.gov.br/doc_tec/imuni/tetra valente.pdf.

12. Kmetzsch CI, Schermann MT, Santana JCB, Estima CL, Faraco FJ, Silva CM, Conceição R. Meningites por Haemophylus influenzae b após a implantação da vacina específica. J Pediatr 2003; 79(6):530-536.

13. Levine OS, Schwartz B, Pierce N, Kane M. Development, evaluation and implementation of Haemophilus influenzae type $\mathrm{b}$ vaccines for young children in developing countries: current status and priority actions. Pediatr Infect Dis J 1998; 17(Supl. 9):95-113.

14. Agudelo CI, Munoz N, De La Hoz F. Evaluación rápida del impacto de la vacuna contra Haemophilus influenzae serotipo b en Colombia. Rev Panam Salud Publica 2000; 8(3)181-183.

15. Brasil. Ministério da Saúde (MS). Secretária de Vigilância em Saúde. Departamento de Vigilância Epidemiológica. Guia de Vigilância Epidemiológica. 4a Edição. Brasília: MS; 1998.

16. Brasil. Ministério da Saúde (MS). Secretária de Vigilância em Saúde. Departamento de Vigilância Epidemiológica. Guia de Vigilância Epidemiológica. 7a Edição. Brasília: MS; 2009.

17. Rey LC, Wolf B, Moreira JLB, Verhoef J, Farhat CK. S. pneumoniae isolados da nasofaringe de crianças sadias e com pneumonia: taxa de colonização e susceptibilidade aos antimicrobianos. J Pediatr 2002; 78(2):105-112.

18. Adegbola AA, Mulhoand EK, Secka O, Jaffar S, Greenwood BM. Vaccination with a Haemophilus influenzae type b conjugate vaccine reduces oropharyngeal carriage of H.influenzae type b among Gambian children. J Infect Dis 1998; 177(6):1758-1761.

19. Miranzi SSC, Moraes AS, Freitas ICM. Tendência das meningites por Haemophilus influenzae tipo b no Brasil, em menores de 5 anos, no período de 1983 a 2002. Revista da Sociedade Brasileira de Medicina Tropical 2006; 39(5):473-477.
20. Redmond SR, Pichichero ME. Haemophilus influenzae type b disease an epidemiological study with special reference to day-care centers. JAMA 1984; 252(18):2581-2584.

21. Borderon JC. Haemophilus influenzae: colonization et infection. Arch Pediatr 1995; 2(3):249-254.

22. Takala AK, Clements DA. Socioeconomic risk factors for invasive Haemophilus influenzae type b disease. J Infect Dis 1992; 165(Supl. 1):11-15.

23. Aniansson G, Alm B, Anderson B, Larsson P, Nylén O, Peterson H, Rignér P, Svanborg M, Svanborg C. Nasopharyngeal colonization during the first year of life. J Infect Dis 1992; 165(Supl. 1):S38-42.

24. Andrade ALSS, Afonso ET, Silva SA, Neto OLM, Marques SM, Martelli CMT. Invasive Disease-related mortality among children before and after the introduction of the Haemophilus influenzae type B conjugate vaccine in Brazil. Int J Infect Dis 2004; 8(Supl. 1):173-181.

25. Lucher LA, Reeves M, Hennessy T, Levine OS, Popovic T, Rosesnstein N, Parkinson AJ. Reemergence in South Western Alaska, of invasive Haemophilus influenzae type b disease due to strains indistinguishable from those isolated from vaccinated children. J Infect Dis 2002; 186(7):958-965.

26. Peerbooms PGM, Engelen MN, Stokman DAJ, van Benthem BHB, van Weert ML, Bruisten SM, van Belkum A, Coutinho RA. Nasopharyngeal carriage of potencial bacterial pathogens related to day care attendance, with special reference to the molecular epidemiology of Haemophilus influenzae. J Clin Microbiol 2002; 40(8):2832-2836.

27. Marin JM. Análise de cepas colonizadoras de Haemophilus influenzae em crianças de creches ligadas a Secretaria de Educação de Ribeirão Preto [tese] Ribeirão Preto: Faculdade de Odontologia de Ribeirão Preto, USP; 2004.

28. McVernon J, Johnson PDR, Polard AJ, Slack MPE, Moxon ER. Immunologic memory in Haemophilus influenzae type $\mathrm{b}$ conjugate vaccine failure. Arch Dis Child 2003; 88(5):379-383.

29. Malta DC, Duarte EC, Almeida MF, Dias MAS, Morais Neto OL, Moura L, Ferraz W, Souza MFM. Lista de causas de mortes evitáveis por intervenções do Sistema Único de Saúde do Brasil. Epidemiol. Serv. Saúde 2007; 16(4):233-244.

Artigo apresentado em 25/03/2012

Aprovado em 15/08/2012

Versão final apresentada em 06/09/2012 